\title{
The Association Between Autistic Traits and Mental Well-Being
}

\author{
Nikolas J. Stimpson ${ }^{1}$ (D) - Laura Hull ${ }^{2}$ (D) William Mandy ${ }^{2}$ \\ Published online: 10 February 2020 \\ (c) The Author(s) 2020
}

\begin{abstract}
It is now accepted that sub-clinical autistic traits are continuously distributed in the general population. It appears that there has been no prior research on the relationship between autistic traits and mental well-being. We explored the nature of such a relationship using multiple regression models. 227 non-clinical adults aged 18-50 years completed an online self-report questionnaire with measures including the Warwick-Edinburgh Mental Wellbeing Scale and the Broad Autism Phenotype Questionnaire (BAPQ). Of the BAPQ subscales, aloofness (social anhedonia) but not rigidity or pragmatic language problems was associated with decreased mental well-being when controlling for extraversion, neuroticism, depression, and self-reported physical health. This association was partially mediated by crisis support (the number of people a respondent felt they could turn to for help in the event of a serious personal crisis). The results suggest that aloofness is a significant negative predictor of mental well-being, and that autistic traits might not be best represented as a single unitary factor in the context of outcomes related to mental well-being. Implications pertaining to the importance of social support and the possible contributing role of low self-perceived social competence to aloofness are discussed.
\end{abstract}

Keywords Autistic traits - Aloofness $\cdot$ Broader autism phenotype $\cdot$ Crisis support $\cdot$ Mental well-being · Warwick-Edinburgh Mental Well-Being Scale

Nikolas J. Stimpson

nikolas.stimpson.12@alumni.ucl.ac.uk

Laura Hull

laura.hull.14@ucl.ac.uk

William Mandy

w.mandy@ucl.ac.uk

1 Faculty of Mathematical and Physical Sciences, UCL, Gower Street, London WC1E 6BT, UK

2 Research Department of Clinical, Educational and Health Psychology, UCL, Gower Street, London WC1E 6BT, UK 


\section{Introduction}

Autism spectrum disorder (ASD) is a complex, heterogeneous neurodevelopmental disorder characterized by difficulties in social communication, restricted or repetitive interests or behaviours (stereotypies), and possible impairments or delays in intellectual and language development (American Psychiatric Association 2013). Although historically viewed as a discrete categorical diagnosis, recent evidence supports the notion that ASD represents the most extreme end of a continuously distributed spectrum of autistic traits present in the general population (Constantino and Todd 2003; Hoekstra et al. 2007; Piven et al. 1997), as illustrated in Fig. 1.

First-degree relatives of those diagnosed with ASD have been found to show mild autistic traits (Constantino et al. 2006; Piven et al. 1997; Sucksmith et al. 2011). These findings helped establish the concept of the broader autism phenotype (BAP), which refers to the presence of autistic characteristics insufficient to meet the criteria for a clinical diagnosis but still associated with a genetic liability to ASD (Hurley et al. 2007; Sucksmith et al. 2011; Wainer et al. 2011). These highly heritable traits are present not only in relatives of individuals with ASD but also in the general population (Constantino and Todd 2003; Hoekstra et al. 2007; Robinson et al. 2011); see Fig. 1. The BAP exists independently of any intellectual disabilities and these traits appear to be relatively stable across the lifetime (Starr et al. 2001).

Despite extensive research interest in the BAP in recent years, little is known about how the BAP relates to general wellbeing and mental health. Based on informant and parent/ caregiver interviews regarding well-being and other factors such as recreational activities, Billstedt et al. (2011) found high quality of life estimates (based on evaluation of five categories developed by the authors) in individuals with ASD diagnoses despite strong dependence on caregivers. Contrary to this, Pisula et al. (2015) found a negative relationship between autistic traits and quality of life, based on the World Health Organization

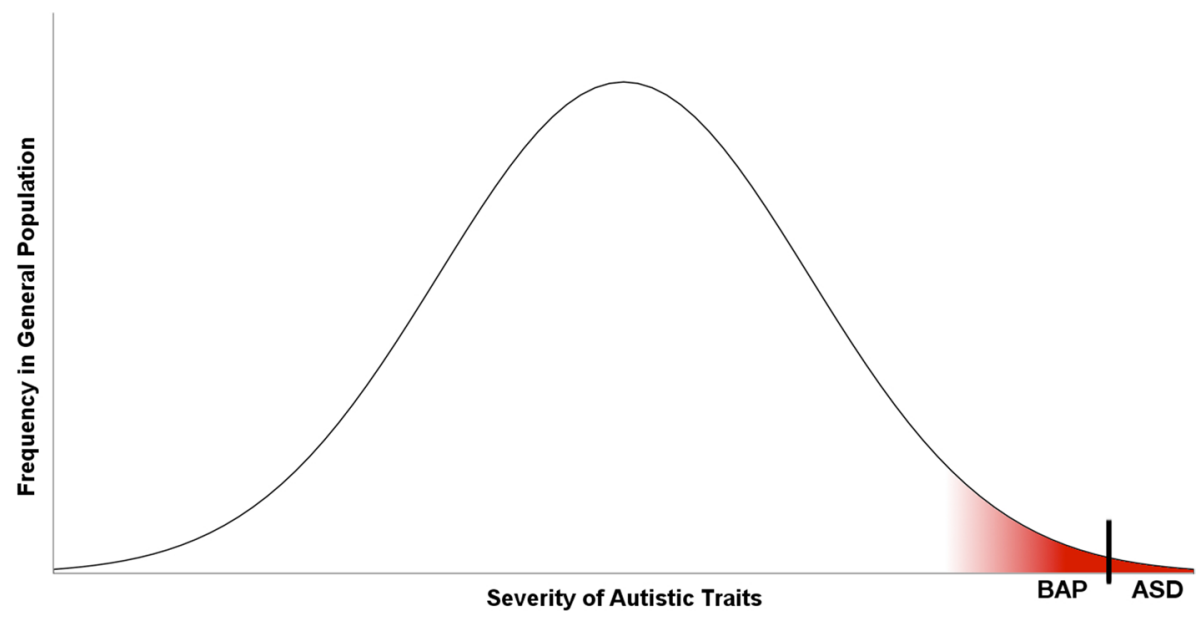

Fig. 1 Illustration of the concept that autistic traits are continuously distributed in the general population. ASD represents the most severe expression of autistic traits while BAP represents a milder, sub-clinical expression of autistic traits. N.b. the line representing the diagnostic threshold for ASD is somewhat arbitrary and ultimately depends on a case-by-case interpretation of diagnostic criteria by a clinician. ASD: autism spectrum disorder; BAP: broader autism phenotype 
Quality of Life-BREF self-report measure. Begeer et al. (2017) found that children with ASD scored lower than typically developing children on "subjective well-being," measured by parents' responses to a 5-point Likert scale item about how happy their child is. Grove et al. (2018) reported that for adults with ASD, increased motivation to engage in special interests was associated with greater "subjective well-being," measured by a composite of scales for satisfaction with life, subjective happiness, and general quality of life. Despite this variety of methods previously used to study quality of life or subjective well-being in clinical ASD samples, it appears that there has been no prior research on the direct relationship between autistic traits and mental well-being (which is a related but distinct concept in comparison to quality of life or subjective well-being) in a non-clinical sample. Nor have individual BAP characteristics (aloofness, rigidity, and pragmatic language problems) been studied in this context.

As a whole, mental well-being can be described as a combination of hedonic and eudaimonic well-being (Myers and Diener 1995; Ryff 1989, 2014) such that positive psychological functioning (not merely the absence of mental illness) is represented; incorporating not only happiness and eudaimonia but also concepts such as agency and self-esteem. Mental well-being is a somewhat broader concept than quality of life, the latter of which may be defined as self-perceived satisfaction with one's position in life with respect to environmental resources and personal goals-with no account for psychological functioning (Langlois and Anderson 2002). The study of well-being within the domain of positive psychology has become more important following findings that greater well-being has significant health benefits. Better mental health appears to be protective against age-related chronic conditions such as back problems and arthritis, even when controlling for confounders such as exercise and body mass index (Keyes 2005). Purpose in life, one of the six dimensions of eudaimonic well-being (Ryff 1989), is associated with reduced risk of stroke (Ryff 1989) and heart attacks (Kim et al. 2013). Reports that greater eudaimonic well-being is associated with lower cortisol levels (Heller et al. 2013; Lindfors and Lundberg 2002) support the notion that well-being can affect biological factors so as to influence physical health. As with autistic traits, it is likely that there is a genetic factor involved in well-being. A study by Lykken and Tellegen (1996) estimated the heritability for the stable (i.e. timeinvariant) component of subjective well-being to be as high as $80 \%$.

Mental well-being and happiness are strongly associated with positive interpersonal relationships and social skills (Argyle and Lu 1990; Demir et al. 2012; Segrin and Taylor 2007), yet ASD is characterized by impaired social communication skills (American Psychiatric Association 2013; Kang et al. 2019). It is unsurprising that Jobe and White (2007) reported increased loneliness associated with the BAP in a non-clinical sample. They suggest that this finding is due to impaired social skills rather than any supposed preference for solitude. Ratner and Burrow (2017) also reported that poor communication skills are associated with a lower sense of purpose in life, moreso than any other autistic feature they measured in the general population. In a clinical ASD sample, loneliness was negatively correlated with perceived social support (Lasgaard et al. 2010). Similarly, Blanchard et al. (2011) found that for participants from a community sample rated high in social anhedonia, having social support was associated with improved general functioning and reduced schizotypal behaviour.

Overall, evidence suggests that social support is associated with greater mental wellbeing, attributable both to social support buffering against adverse effects from stressful events and to positive affect gained through regularized social interaction (Cohen and Wills 1985). Potentially lower social support in the BAP should be considered in any potential relationship between autistic traits and mental well-being. For example, a person less 
inclined or less able to develop and maintain long-term friendships might have fewer contacts available to rely on in the event of a serious personal crisis, which would then be detrimental to mental well-being.

It has also been established that aspects of mental well-being including eudaimonia, happiness, and life satisfaction are particularly associated with high extraversion as well as low neuroticism (Costa and McCrae 1980; Francis 1998; Hayes and Joseph 2003; Robbins et al. 2010; Kokko et al. 2013; Gale et al. 2013) regardless of the amount of time spent in social settings (Pavot et al. 1990). In contrast, autistic traits are associated with low extraversion and high neuroticism (Austin 2005; Piven et al. 1997; Wakabayashi et al. 2006). Piven et al. (1997) note that the association of autistic traits with neuroticism may be explained by greater anxiety found in BAP fathers and greater hypersensitivity to criticism found in BAP mothers, as both anxiety and hypersensitivity to criticism correlate with neuroticism.

The extent to which autistic traits directly influence mental well-being is of considerable interest because such traits might represent population-level risk factors for poor mental well-being (and consequential health risks). Therefore, our primary objective was to determine what relationship, if any, exists between the presence of autistic traits in a nonclinical individual and one's mental well-being. Secondly, we aimed to assess how such a relationship might be influenced by other characteristics such as gender, personality, socioeconomic status (SES), or degree of social support. As autistic traits are associated with higher levels of mental health conditions including anxiety and depression (Radtke et al. 2019), which contribute significantly to mental well-being, we aimed to control for these characteristics as well. Other control variables included (a) self-reported physical health, as Braunholtz et al. (2007) concluded that people who self-reported poor physical health "were less likely to feel they could control the circumstances that might affect their sense of mental wellbeing."; (b) degree type, as there is evidence that science students are likely to score higher on measures of autistic traits than other students (Austin 2005; BaronCohen et al. 2001); and (c) unpaid care, as there is evidence that informal caregiving is a chronic stress experience which can contribute to feeling burdened and overwhelmed (e.g. Yates et al. 1999; Schulz and Sherwood 2008), and thus may negatively influence mental well-being.

We predicted that there would be a negative relationship between all dimensions of autistic traits and mental well-being. In support of prior research (Austin 2005; Hoekstra et al. 2007), we also predicted that males, on average, would demonstrate significantly greater autistic traits than females. Finally, we predicted that any association between autistic traits and mental well-being will be at least partially mediated by social support, measured here by available crisis support.

\section{Methods}

\subsection{Participants}

This study was conducted online. Participants were recruited through internet advertisements, student subject pools, and social media channels. Participants were fluent English speakers aged 18-50 years. Of 379 respondents, 4 were excluded for being outside the age range, 29 were excluded for having a current diagnosis of a mental health disorder, ASD, or intellectual disability, 23 were excluded for failing to correctly answer a validity test 
question (indicating inattentiveness), and 96 were excluded for failing to finish the survey. Responses from a final sample of 227 participants were analyzed. The mean age was 28.4 years $(S D=8.42$, range $=18-50)$ (one participant affirmed they were within the $18-50$ range but declined to provide their exact age, and was excluded from analyses involving that variable) and $56.4 \%$ of participants were female $(n=128)$. Participants were residents of the United Kingdom $(n=76)$, United States of America $(n=69)$, Canada $(n=39)$, and thirty other countries $(n=43)$.

As a reward for completing the questionnaire, participants were offered the chance to enter a prize draw for one of eight online shopping vouchers worth $£ 25.00$ each. All participants gave informed consent prior to starting the questionnaire and upon completion they were also given a written debrief further explaining the study's aims. This study was approved by the Research Ethics Committee at University College London.

\subsection{Measures}

Participants completed the following measures sequentially in an online self-report questionnaire. The questionnaire was designed to take approximately $15 \mathrm{~min}$ to complete.

\subsubsection{Mental Well-Being}

Mental well-being was measured with the Warwick-Edinburgh Mental Well-Being Scale (WEMWBS; Taggart et al. 2015). This 14-item questionnaire encompasses most aspects of hedonic and eudaimonic well-being together with positive mental health and psychological functioning. Each item presents a positively-worded statement (e.g. "I've been feeling good about myself") and participants use a 5-point Likert-type scale to indicate how often the statement has applied to them over the past two weeks. A final WEMWBS score is calculated from the sum of all 14 item scores. The WEMWBS has good construct validity, face validity, cross-cultural validity, test-retest reliability (intraclass correlation $=.83$ ), and internal consistency (Cronbach's alpha $=0.91$, Taggart et al. 2015); it also has no significant ceiling or floor effects and population-level WEMWBS scores are normally distributed (Taggart et al. 2015).

\subsubsection{Autistic Traits}

The presence of sub-clinical autistic traits was measured with the Broader Autism Phenotype Questionnaire (BAPQ; Hurley et al. 2007). The BAPQ is a 36-item measure that consists of three 12-item subscales that each correspond to the three main characteristics of the BAP and autism: the Aloof Personality ('Aloofness') subscale reflects social anhedonia; the Rigid Personality ('Rigidity') subscale reflects a desire for repetitive stereotyped routines and behaviour; and the Pragmatic Language Problems subscale reflects deficits in social communication abilities. Each BAPQ item presents a statement (e.g. "I would rather talk to people to get information than to socialize" in the aloofness subscale, "I feel a strong need for sameness from day to day" in the rigidity subscale, and "I leave long pauses in conversation" in the pragmatic language problems subscale) and participants use a 6-point Likert-type scale to indicate how often that statement applies to them. A final BAPQ score is computed from the average of all 36 item scores and each subscale is scored from the average of the 12 relevant items (some individual items are reverse-scored where appropriate). The BAPQ and its subscales are highly sensitive and specific for detecting the BAP 
(Hurley et al. 2007), and it demonstrates good model invariance across genders (Broderick et al. 2015). The BAPQ and its subscales also have good inter-item reliability (Cronbach's alpha $=.95$ overall, .94 for aloofness, .91 for rigidity, and .85 for pragmatic language problems; Hurley et al. 2007).

Along with demographic information and SES indicators including age, gender, country of residence, terminal education age, occupation, marital status, and household tenure, selected background factors previously reported to correlate with either mental well-being (e.g. Braunholtz et al. 2007; Gale et al. 2013; Kokko et al. 2013; Taggart et al. 2015) or autistic traits (e.g. Austin 2005; Baron-Cohen et al. 2001; Wakabayashi et al. 2006) were measured to control for possible confounders.

\subsubsection{Personality Traits}

Extraversion and neuroticism were measured using the relevant subscales of the Big Five Inventory (BFI; John et al. 1991). Both subscales consist of eight items presenting statements about certain characteristics (e.g., "I see myself as someone who is talkative") and the participant responds with how much they agree or disagree with the statement using a 5-point Likert scale. Final scores for extraversion and neuroticism are computed from the sum of each item score in the 8-item subscale (some individual items are reverse-scored where appropriate). The BFI was designed as a briefer and less ambiguous alternative to lengthier personality scales; the extraversion and neuroticism subscales have good overall validity and reliability (coeffieicnt alpha $=.88$ for extraversion, .84 for neuroticism; John and Srivastava 1999).

\subsubsection{Anxiety Severity}

Anxiety was measured using the Generalized Anxiety Disorder 7-item scale (GAD-7) developed by Spitzer et al. (2006). Each GAD-7 item presents a problem statement (e.g. "worrying too much about different things") and the participant uses a 4-point Likert-type scale to indicate how often the statement applied to them over the past two weeks. If any problems are indicated, the participant is asked about their anxiety symptom-related difficulty using a 4-point Likert-type scale to indicate how difficult the problems have made their ability to "... work, take care of things at home, or get along with other people." The GAD-7 has good overall internal consistency (Cronbach's alpha $=.92)$, test-retest reliability (intraclass correlation $=.83$ ), validity, sensitivity, and specificity (Spitzer et al. 2006).

\subsubsection{Depression}

Depression was measured using the 2-item Patient Health Questionnaire depression module (PHQ-2), a shortened version of the 9-item PHQ used to identify features of depression (Kroenke et al. 2003). The two items present statements about depressed mood and anhedonia and participants use a 4-point Likert-type scale to indicate how frequently those symptoms have affected them over the past 2 weeks. A final PHQ-2 score is computed from the sum of both item scores. The PHQ-2 correlates strongly with mental health and demonstrates good criterion and construct validity (Kroenke et al. 2003), as well as good internal reliability (Cronbach's alpha $=.81$; Kroenke et al. 2009). With final scores ranging from 0 to 6, the PHQ-2 provides a continuous variable for depressed mood and anhedonia 
without including additional items pertaining to a clinical diagnosis of depression, which is beyond the scope of this study.

\subsubsection{Self-Reported Health}

Participants were asked "how would you describe your state of physical health in general?" and responded using a 5-point Likert-type scale ( $1=$ Very Good to $5=$ Very Poor, or "I don't know"). This item was reverse-scored and responses of "I don't know" were excluded from analyses involving this measure. This measure (and variants of it) is very common in health research, and is considered to have good reliability (weighted $\kappa=.75,95 \%$ CI .71 to .79; Andresen et al. 2003).

\subsubsection{Degree Type}

Participants who were current or prior college/university students were asked to describe their degree type or area of study.

\subsubsection{Parental Educational Attainment}

Participants categorized the educational attainment of their mother and father separately as having no formal education, some secondary education, completed secondary education and/or training below bachelor's level, bachelor's level, master's level, or doctorate level and above. Responses of "other" were specified and coded appropriately, and responses of "don't know" were excluded from analyses involving this measure.

\subsubsection{Unpaid Care}

Participants categorized the amount of time they typically spent providing unpaid care to relatives, friends, or neighbours (e.g. because of problems related to old age) as none, less than $5 \mathrm{~h}$ per week, 5-34 h per week, or more than $34 \mathrm{~h}$ per week.

\subsubsection{Contact with Friends and Relatives}

Participants were asked, "On average, how often do you see friends or relatives who are not living with you?" and responded using a 5-point Likert-type scale $(1=$ Never to $5=$ Most days).

\subsubsection{Crisis Support}

Participants were asked to provide a number indicating how many people they felt they could turn to for comfort and support in the event of a serious personal crisis.

\subsection{Power Analysis}

Previous research exploring the relationship between the BAPQ and social cognition (Sasson et al. 2012) and between the BAPQ and measures of friendship (Jamil et al. 2017) has reported small-medium correlations of between $r=.22$ and $r=.30$. Post-hoc power analysis 
using $G^{*}$ Power version 3.1 (Faul et al. 2007) confirmed that the sample size of 227 was sufficient to detect correlations of this size with power $=0.95$. The sample of 227 also exceeds the minimum recommendation of 135 to detect significant individual differences ( \pm 3 points) in WEMWBS scores (Taggart et al. 2015).

\subsection{Data Analysis}

The collected data were analysed using SPSS version 22.0 (IBM Corp., Armonk, NY). In cases of missing data for one or two items on a measure, the missing data were replaced with the respondent's average score for that measure. One respondent skipped 26 BAPQ items and was excluded from analyses involving the BAPQ.

Possible gender differences for continuous variables were analyzed using 2-tailed Student's $t$ tests of independent samples; homogeneity of variance was confirmed in all cases using Levene's Test for Equality of Variance. Cohen's $d$ coefficients were calculated to determine effect sizes of gender. Pearson's product-moment correlation coefficients were calculated between all continuous variables using 2-tailed significance tests. Internal consistencies for scales comprising more than one item were calculated using Cronbach's alpha.

An initial multiple regression analysis for mental well-being was conducted using BAP dimensions (aloofness, rigidity, and pragmatic language problems), and possible confounders from the continuous and ordinal variables as predictors. Aloofness emerged as the only BAP dimension that was a significant predictor of mental well-being when controlling for extraversion, neuroticism, anxiety, depression, age, self-reported health, parental educational attainment, time spent giving unpaid care, and contact with friends and relatives. Crisis support was not entered into the model at this stage as it was considered a possible mediator (rather than a confounder) of the association between aloofness and mental well-being. Before testing this mediation effect, nominal variables were assessed as possible confounders using one-way analyses of variance (ANOVAs); homogeneity of variance was confirmed using Levene's Test for Equality of Variance or Welch's ANOVA test as appropriate.

Non-significant predictors were removed and a final set of predictors was identified. The interaction term between aloofness and gender was entered into the regression model to test for a possible moderation effect of gender. Lastly, separate linear regressions were conducted to determine if the relationship between aloofness and mental well-being was mediated by crisis support, using version 2.15 of the PROCESS macro for SPSS (Hayes 2013). In all regression models, multicollinearity levels were considered and deemed acceptable based on relatively low variance inflation factors (VIFs; O'Brien 2007).

\section{Results}

\subsection{Initial Correlations}

Descriptive statistics for measured continuous variables are displayed in Table 1. Student's $t$ tests (2-tailed) revealed that females scored significantly lower than males on all subscales of the BAPQ and on depression, significantly higher than males on extraversion, and were significantly older than male respondents. There were no other significant gender 
Table 1 Descriptive statistics of continuous variables

\begin{tabular}{lllrrrr}
\hline Variable & Min & Max & \multicolumn{1}{c}{ Mean $(S D)$} & \multicolumn{1}{c}{$\operatorname{Mean}_{\mathrm{M}}(S D)$} & $\operatorname{Mean}_{\mathrm{F}}(S D)$ & $d_{\text {gender }}$ \\
\hline Mental well-being & 23 & 70 & $46.02(8.93)$ & $45.90(8.11)$ & $46.11(9.55)$ & 0.02 \\
Autistic traits (total) & 1.56 & 5.36 & $3.25(0.70)$ & $3.46(0.68)$ & $3.08(0.68)$ & $-0.55 * *$ \\
Aloofness & 1.17 & 6.00 & $3.61(1.04)$ & $3.91(0.98)$ & $3.38(1.04)$ & $-0.53 * *$ \\
Rigidity & 1.08 & 5.50 & $3.23(0.86)$ & $3.37(0.88)$ & $3.12(0.82)$ & $-0.30 *$ \\
PLP & 1.25 & 5.00 & $2.90(0.69)$ & $3.08(0.69)$ & $2.76(0.65)$ & $-\mathbf{0 . 4 9 * * *}$ \\
Extraversion & 8 & 40 & $21.10(7.66)$ & $19.52(7.16)$ & $22.33(7.83)$ & $\mathbf{0 . 3 7 * *}$ \\
Neuroticism & 8 & 40 & $24.16(6.70)$ & $23.28(6.61)$ & $24.84(6.71)$ & 0.23 \\
Anxiety & 0 & 21 & $6.55(4.97)$ & $6.47(4.77)$ & $6.61(5.14)$ & 0.03 \\
Depression & 0 & 6 & $1.75(1.59)$ & $1.99(1.65)$ & $1.56(1.52)$ & $\mathbf{- 0 . 2 7 *}$ \\
Crisis support & 0 & 20 & $5.22(3.76)$ & $4.95(3.76)$ & $5.43(3.76)$ & 0.13 \\
Age & 18 & 50 & $28.39(8.42)$ & $26.69(8.27)$ & $29.69(8.34)$ & $\mathbf{0 . 3 6 * *}$ \\
\hline
\end{tabular}

Means are shown for the total sample, and for each gender. $d$ coefficients indicate the effect size of gender on mean score differences such that a positive effect size corresponds to higher scores in females

$P L P$ pragmatic language problems, $M$ male subset, $F$ female subset

$* p<.050 ; * * p<.010 ; * * * p<.001$

differences. The effect sizes for these differences (calculated using Cohen's $d$ ), displayed in Table 1, can be described as small-medium (Cohen 1988).

Pearson's product moment correlation coefficients between continuous variables are shown in Table 2. As expected, there was a negative correlation between mental well-being and overall autistic traits $(r=-.59, p<.001)$, mostly between mental well-being and aloofness $(r=-.55, p<.001)$. There was also a large negative correlation between overall autistic traits and extraversion $(r=-.71, p<.001)$, and a positive correlation between overall autistic traits and neuroticism $(r=.46, p<.001)$.

The observation of only medium-sized correlations between aloofness and rigidity $(r=.52, p<.001)$, aloofness and pragmatic language problems $(r=.50, p<.001)$, and rigidity and pragmatic language problems $(r=.44, p<.001)$ suggests that these scales are measuring somewhat independent factors, so total BAPQ scores were excluded from further analyses in favour of these subscales.

\subsection{Internal Consistency}

Using Cronbach's alpha, the scales used in this study were found to have acceptable reliability (Mental well-being, $\alpha=.90$; Autistic traits (total), $\alpha=.87$; Aloofness, $\alpha=.93$; Rigidity, $\alpha=.89$; Pragmatic language problems, $\alpha=.78$; Extraversion, $\alpha=.90$; Neuroticism; $\alpha=.85$; Anxiety, $\alpha=.88$; Depression, $\alpha=.74$ ).

\subsection{Multiple Regression Model: Initial Analysis}

A multiple regression analysis was conducted to determine how well each BAP dimension predicted mental well-being with the potential confounders of extraversion, neuroticism, anxiety, depression, age, self-reported health, parental educational attainment, time spent giving unpaid care, and contact with friends and relatives added into the model. It was 


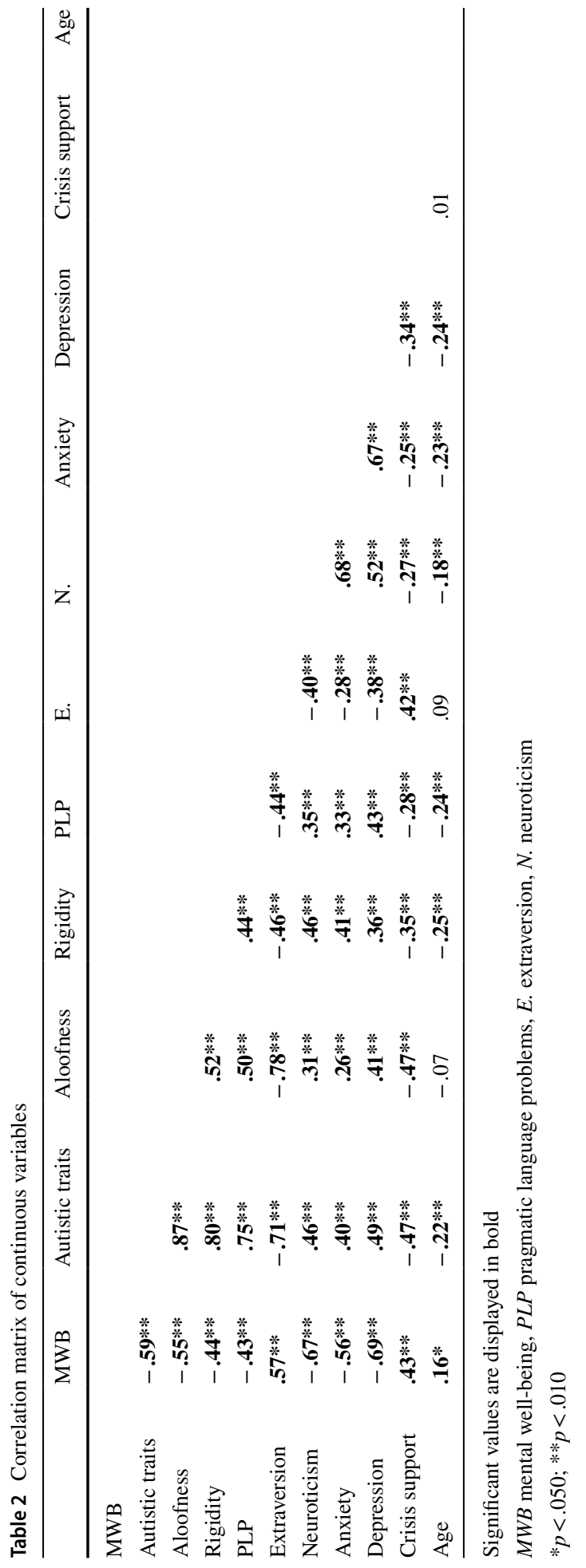


found that only aloofness, extraversion, neuroticism, depression, and self-reported health were significant predictors. The completed initial regression model is shown in Table 3. Together, approximately $66 \%$ of the variance in mental well-being was explained by aloofness, extraversion, neuroticism, depression, and self-reported health $\left(R^{2}=.685\right.$, adjusted $\left.R^{2}=.664\right)$.

Because there were significant bivariate correlations between the variables used in the regression (Table 2), we were concerned about possible problems arising from multicollinearity. However, VIFs (the inverse of the Tolerance, which is defined as $1-R^{2}$ for each variable) were found to be well below the conventional thresholds of 10 for serious multicollinearity or 5 for concern (O'brien 2007).

Mental well-being was negatively predicted by aloofness $\left(\beta=-.144, t_{197}=-1.99\right.$, $p=.047)$, neuroticism $\left(\beta=-.375, t_{197}=-6.27, p<.001\right)$, and depression $(\beta=-.413$, $\left.t_{197}=-6.96, p<.001\right)$. Mental well-being was positively predicted by extraversion $\left(\beta=.133, t_{197}=1.96, p=.051\right)$ and self-reported health $\left(\beta=.103, t_{197}=2.28, p=.023\right)$.

Using one-way ANOVAs (and Welch's ANOVA where appropriate), occupation, terminal education age, degree type, marital status, and household tenure were determined not to be significant confounders of the association between mental well-being and aloofness.

\subsection{Moderation and Mediation Analyses: Gender and Crisis Support}

Because significant gender differences in aloofness were found (Table 1), the interaction term of gender and aloofness was entered into the regression model as a possible moderator. Gender was not found to significantly moderate the relationship between aloofness and mental well-being $\left(\Delta R^{2}=0.004, F_{(1,208)}=2.83, p=.094\right)$.

To test the hypothesis that crisis support mediated the relationship between aloofness and mental well-being, simple linear regression models were constructed. As expected, aloofness was a significant negative predictor of both mental well-being $(b=-4.57$,

Table 3 Initial multiple regression model of mental well-being

\begin{tabular}{lrrrrr}
\hline Variable & $\begin{array}{c}\text { Unstandardized } \\
\text { coefficient } b(S E)\end{array}$ & $\begin{array}{l}\text { Standardized } \\
\text { coefficient } \beta\end{array}$ & \multicolumn{1}{c}{$t$} & $p$ & VIF \\
\hline (Constant) & $60.241(5.431)$ & & 11.09 & $<. \mathbf{0 0 1}$ \\
Aloofness & $-1.223(0.612)$ & -0.144 & -1.99 & $\mathbf{. 0 4 7}$ & 3.236 \\
Rigidity & $0.169(0.561)$ & 0.016 & 0.30 & .764 & 1.774 \\
Pragmatic language problems & $0.082(0.651)$ & 0.006 & 0.13 & .900 & 1.561 \\
Extraversion & $0.158(0.080)$ & 0.133 & 1.96 & $\mathbf{. 0 5 1}$ & 2.863 \\
Neuroticism & $-0.500(0.080)$ & -0.375 & -6.27 & $<. \mathbf{0 0 1}$ & 2.236 \\
Anxiety & $0.109(0.120)$ & 0.059 & 0.90 & .366 & 2.690 \\
Depression & $-2.419(0.348)$ & -0.413 & -6.96 & $<.001$ & 2.202 \\
Age & $-0.044(0.049)$ & -0.043 & -0.91 & .363 & 1.368 \\
Self-reported health & $1.051(0.460)$ & 0.103 & 2.28 & $\mathbf{. 0 2 3}$ & 1.264 \\
Mother's educational attainment & $-0.240(0.332)$ & -0.034 & -0.72 & .470 & 1.352 \\
Father's educational attainment & $-0.219(0.303)$ & -0.034 & -0.72 & .470 & 1.342 \\
Unpaid care hours & $0.577(0.615)$ & 0.040 & 0.94 & .349 & 1.164 \\
Contact with friends and relatives & $0.095(0.340)$ & 0.012 & 0.28 & .780 & 1.139 \\
\hline
\end{tabular}

Significant values are displayed in bold 
$\left.S E=.49, t_{221}=-9.39, p<.001\right)$ and crisis support $\left(b=-1.67, S E=.21, t_{221}=-8.01\right.$, $p<.001)$. When a regression model for mental well-being was formed with both aloofness and crisis support as predictors, aloofness was weakened as a predictor of mental wellbeing $\left(b=-3.68, S E=.54, t_{220}=-6.82, p<.001\right)$. This result indicates a partial mediation effect of crisis support in the association between aloofness and mental well-being (Fig. 2). This indirect effect was found to be significant when tested using bootstrapped estimation (Preacher and Hayes 2004) with 1000 samples $(b=-0.89, S E=.27,95 \% \mathrm{CI}-1.49$, -0.42 ). Approximately $20 \%$ of the association between mental well-being and aloofness was mediated by crisis support.

\section{Discussion}

In support of our hypothesis, mental well-being correlated negatively with overall autistic traits in this non-clinical sample. However, of the three BAPQ subscales corresponding to the three primary characteristics of the BAP (aloofness, rigidity, and pragmatic language problems), aloofness emerged as the only significant predictor of mental well-being when controlling for extraversion, neuroticism, depression, and self-reported physical health. Males scored higher than females on all measures of autistic traits, but gender was not a significant moderator of the relationship between aloofness and mental well-being. The association between aloofness and mental well-being was partially mediated by crisis support.

The three BAPQ subscales were only modestly intercorrelated (Table $1 ; r=.44$ to .52 , $p<.010$ ). These results support the argument of Happé et al. (2006) that the different dimensions of autistic traits should be studied separately (due to potentially independent causal factors) rather than combined into a single unitary factor. Our results also agree with findings by Kim et al. (2018) that the ASD phenotype is most optimally characterized by three separate domains rather than as a single categorical syndrome. Had the BAPQ subscales not been analyzed individually in the present study, the dominance of aloofness over rigidity or pragmatic language problems in relation to mental well-being may not have been identified.

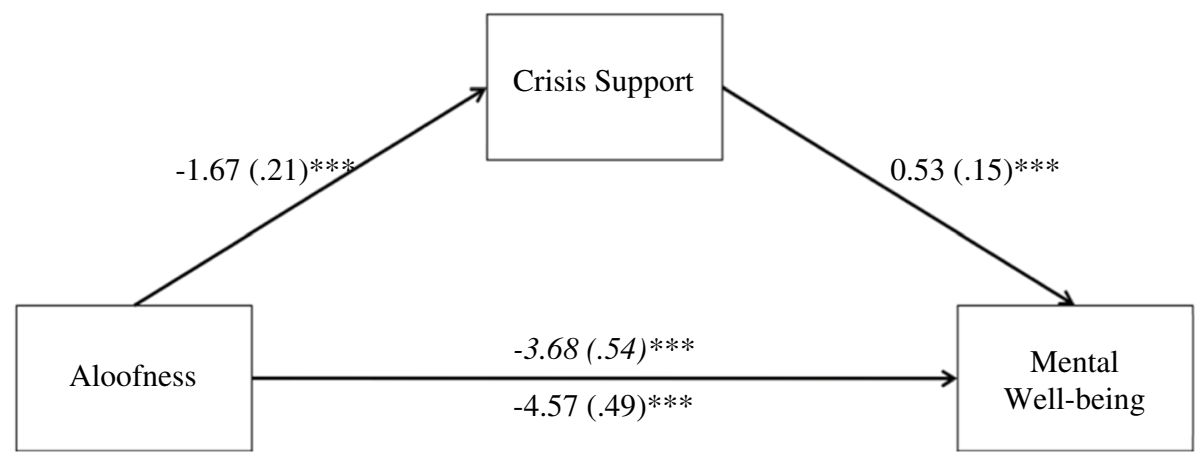

Fig. 2 Mediation Model for Crisis Support on the Association Between Aloofness and Mental Well-Being. Unstandardized b coefficients between variables are displayed (with standard errors in brackets). The unstandardized $\mathrm{b}$ coefficient between aloofness and mental well-being when controlling for the mediation effect of crisis support is italicized. $* * * p<.001$ 
The difference between aloofness and extraversion should also be made clear: in the final regression model, aloofness and extraversion predicted mental well-being independently of each other (and in different directions) so it can be said that they represent somewhat distinct concepts and are not merely opposites of a single continuum. Whereas aloofness as measured in the BAPQ reflects "a lack of interest in or enjoyment of social interaction" (Hurley et al. 2007), extraversion as measured in the BFI reflects not only sociability but also energetic engagement with the external (material) world (John and Srivastava 1999).

The novel finding that aloofness, but not rigidity or pragmatic language problems, is a significant predictor of poorer mental well-being is important because it suggests that the apparent negative association between autistic traits and mental well-being could stem from factors specific to aloofness rather than autistic traits as a whole. One such factor tested in the present analysis was the role of crisis support as a partial mediator. Our results were consistent with previous research suggesting that social support is protective against poorer mental well-being in vulnerable populations (e.g. Blanchard et al. 2011; Lasgaard et al. 2010).

\subsection{Limitations}

While this project was designed to control for many possible confounding variables, all of which were tested thoroughly, in some cases this effort was hindered by unequal group sizes or variances. This study was underpowered to detect small-sized effects (where $r<0.19$; see Gignac and Szodorai 2016), therefore it is possible that small but significant confounding variables were missed in this analysis. For example, it could be speculated that people predisposed towards greater aloofness would be more likely to undertake degree programmes that have greater impacts on mental well-being, but such an effect was not detected in this study. A more detailed measure of social support (rather than the single crisis support question used in this study) such as the Social Support Questionnaire (Sarason et al. 1983) could be a stronger mediator in future studies.

The correlational nature of this study does not allow causal conclusions to be drawn. It should also be noted that only self-report measures were used. There was no evaluation of possible response biases such as social desirability effects, although participants completed the questionnaire online rather than in-person and were aware that all responses were anonymous. Replications that corroborate these self-report measures with informant or observational data might contribute further to the conclusions presented here. We also suggest that future research into the relationship between the non-clinical expression of autistic traits and mental well-being may benefit from analysis focussed more specifically on comparing larger samples of low-BAP and high-BAP populations.

\subsection{Implications}

Following these findings, the question remains as to whether or not aloofness has a true causal effect on mental well-being. While social skills and communication training could potentially alleviate pragmatic language problems (Bauminger 2002), it is unclear (and even unlikely, as our findings support the relative independence of the BAP dimensions) if a reduction in one BAP dimension would translate to a reduction in aloofness. Rather, future studies could focus on identifying and testing possible factors mediating the relationship between aloofness and mental well-being (including social support) or identifying factors that contribute to aloofness. Having regular recreation activities has been found to 
correlate with better quality of life in a clinical ASD sample (Billstedt et al. 2011). These activities do not necessarily involve interaction with others but do represent some form of engagement with one's external world. Based on this and our results, investigating the relationship between aloofness, type and frequency of recreational activities, and mental wellbeing presents one possible avenue of future research. However, it should be emphasized here that unlike other measures of autistic traits such as the Autism Quotient (Baron-Cohen et al. 2001), the BAPQ was designed to measure autistic traits in adults without a clinical ASD diagnosis and the conclusions of this study cannot be generalized to clinical populations. Rather, our findings highlight a significant association between autistic traits-particularly aloofness - and mental well-being in the general population.

Another consideration is the possible role of self-perceived social competence in the association between aloofness and mental well-being. In children with "high-functioning" ASD, lower self-perceived social competence is associated with depressive symptomatology (Vickerstaff et al. 2007). Aloofness (in this sense, a lack of social motivation) could be a cause of lower self-perceived social competence. More plausibly, lower self-perceived social competence could contribute to aloofness, and thus self-perceived social competence might be a target for interventions aimed at increasing mental well-being.

Social competence in individuals with higher autistic traits may also be affected by modulated perceptual skills associated with ASD. Using behavioural and pupillometric measures, Lawson et al. (2017) demonstrated that adults with ASD tend to overestimate the volatility of their environments, which is associated with decreased surprise when expectations are violated. They also reported that this finding extended to non-clinical adults who exhibited autistic traits. This overestimation of environmental volatility combined with a preference for sameness (rigidity) could be detrimental to forming stable social relationships. Also detrimental to social competence would be perceptual impairments in facial recognition, which also appear to generalize to non-clinical adults with greater expression of autistic traits (Hadad et al. 2019). Future research should examine the possibly moderating role of cognitive and perceptual effects on self-perceived social competence in the association between aloofness and mental well-being.

It has been reported that different strategies for coping with stress can have mediation effects on the relationship between autistic traits and quality of life (Pisula et al. 2015). This is another factor to consider when designing future studies, and could provide an explanation for the observed small but significant negative correlation between age and autistic traits in this study; over time a person may develop strategies for coping with stress which enable that person to attenuate or obscure the effects of autistic traits.

\subsection{Conclusions}

In summary, aloofness was identified as a significant predictor of poor mental well-being when controlling for extraversion, neuroticism, depression, and self-reported physical health in a sample of non-clinical adults. Together these predictors explained approximately $67 \%$ of the variance in mental well-being. Other autistic traits (rigidity and pragmatic language problems) were not significant predictors in this model, nor were anxiety, age, parental educational attainment, time spent giving unpaid care, or frequency of contact with friends and relatives. A partial mediation effect of crisis support on the association between aloofness and mental well-being points to the importance of reliable and supportive social relationships for mental well-being even among those who do not typically enjoy social interactions as much as others. In the long-term, further disentanglement of 
the relationships between autistic traits, social support, and mental well-being could eventually help pinpoint candidate genes for the heterogeneous components of ASD. Next steps will involve more testing of the predictive validity of aloofness for mental well-being and seeking potential causal relationships.

Acknowledgments The Warwick-Edinburgh Mental Well-being Scale was funded by the Scottish Government National Programme for Improving Mental Health and Well-being, commissioned by NHS Health Scotland, developed by the University of Warwick and the University of Edinburgh, and is jointly owned by NHS Health Scotland, the University of Warwick and the University of Edinburgh.

Funding This research did not receive any specific grant from funding agencies in the public, commercial, or not-for-profit sectors.

\section{Compliance with Ethical Standards}

Conflict of interest The authors declare no conflicts of interest.

Open Access This article is licensed under a Creative Commons Attribution 4.0 International License, which permits use, sharing, adaptation, distribution and reproduction in any medium or format, as long as you give appropriate credit to the original author(s) and the source, provide a link to the Creative Commons licence, and indicate if changes were made. The images or other third party material in this article are included in the article's Creative Commons licence, unless indicated otherwise in a credit line to the material. If material is not included in the article's Creative Commons licence and your intended use is not permitted by statutory regulation or exceeds the permitted use, you will need to obtain permission directly from the copyright holder. To view a copy of this licence, visit http://creativecommons.org/licenses/by/4.0/.

\section{References}

American Psychiatric Association. (2013). Diagnostic and manual of mental disorders. Arlington, VA: American Psychiatric Publishing.

Andresen, E. M., Catlin, T. K., Wyrwich, K. W., \& Jackson-Thompson, J. (2003). Retest reliability of surveillance questions on health related quality of life. Journal of Epidemiology and Community Health, 57(5), 339-343.

Argyle, M., \& Lu, L. (1990). Happiness and social skills. Personality and Individual Differences, 11(12), $1255-1261$.

Austin, E. J. (2005). Personality correlates of the broader autism phenotype as assessed by the Autism Spectrum Quotient (AQ). Personality and Individual Differences, 38(2), 451-460. https://doi.org/10.1016/j. paid.2004.04.022.

Baron-Cohen, S., Wheelwright, S., Skinner, R., Martin, J., \& Clubley, E. (2001). The autism-spectrum quotient (AQ): Evidence from asperger syndrome/high-functioning autism, males and females, scientists and mathematicians. Journal of Autism and Developmental Disorders, 31(1), 5-17. https://doi. org/10.1023/A:1005653411471.

Bauminger, N. (2002). The facilitation of social-emotional understanding and social interaction in highfunctioning children with autism: Intervention outcomes. Journal of Autism and Developmental Disorders, 32(4), 283-298.

Begeer, S., Ma, Y., Koot, H. M., Wierda, M., van Beijsterveldt, C. T., Boomsma, D. I., et al. (2017). Brief Report: Influence of gender and age on parent reported subjective well-being in children with and without autism. Research in Autism Spectrum Disorders, 35, 86-91.

Billstedt, E., Gillberg, I. C., \& Gillberg, C. (2011). Aspects of quality of life in adults diagnosed with autism in childhood: A population-based study. Autism, 15(1), 7-20. https://doi.org/10.1177/1362361309 346066.

Blanchard, J. J., Collins, L. M., Aghevli, M., Leung, W. W., \& Cohen, A. S. (2011). Social anhedonia and schizotypy in a community sample: The Maryland longitudinal study of schizotypy. Schizophrenia Bulletin, 37(3), 587-602. https://doi.org/10.1093/schbul/sbp107. 
Braunholtz, S., Davidson, S., Myant, K., Ipsos MORI, \& O'Connor, R. (2007). Well? What do you think?(2006): The third national Scottish survey of public attitudes to mental health, mental wellbeing and mental health problems. Scottish Government Social Research.

Broderick, N., Wade, J. L., Meyer, J. P., Hull, M., \& Reeve, R. E. (2015). Model invariance across genders of the broad autism phenotype questionnaire. Journal of Autism and Developmental Disorders, 45(10), 3133-3147. https://doi.org/10.1007/s10803-015-2472-z.

Cohen, J. (1988). Statistical power analysis for the behavioral sciences (2nd ed.). Hillsdale, NJ: Lawrence Earlbaym Associates.

Cohen, S., \& Wills, T. A. (1985). Stress, social support, and the buffering hypothesis. Psychological Bulletin, 98(2), 310 .

Constantino, J. N., Lajonchere, C., Lutz, M., Gray, T., Abbacchi, A., McKenna, K., et al. (2006). Autistic social impairment in the siblings of children with pervasive developmental disorders. The American Journal of Psychiatry, 163(2), 294-296. https://doi.org/10.1176/appi.ajp.163.2.294.

Constantino, J. N., \& Todd, R. D. (2003). Autistic traits in the general population. Archives of General Psychiatry, 60, 524-530. https://doi.org/10.1001/archpsyc.60.5.524.Text.

Costa, P. T., \& McCrae, R. R. (1980). Influence of extraversion and neuroticism on subjective well-being: Happy and unhappy people. Journal of Personality and Social Psychology, 38(4), 668-678. https://doi. org/10.1037/0022-3514.38.4.668.

Demir, M., Jaafar, J., Bilyk, N., \& Mohd Ariff, M. R. (2012). Social skills, friendship and happiness: A cross-cultural investigation. The Journal of Social Psychology, 152(3), 379-385.

Faul, F., Erdfelder, E., Lang, A.-G., \& Buchner, A. (2007). G*Power 3: A flexible statistical power analysis program for the social, behavioral, and biomedical sciences. Behavior Research Methods, 39, 175-191.

Francis, L. J. (1998). Happiness is a thing called stable extraversion: A further examination of the relationship between the Oxford Happiness Inventory and Eysenck's dimensional model of personality and gender. Personality and Individual Differences, 26(1), 5-11. https://doi.org/10.1016/S0191 $-8869(98) 00185-8$.

Gale, C. R., Booth, T., Mõttus, R., Kuh, D., \& Deary, I. J. (2013). Neuroticism and extraversion in youth predict mental wellbeing and life satisfaction 40 years later. Journal of Research in Personality, 47(6), 687-697.

Gignac, G. E., \& Szodorai, E. T. (2016). Effect size guidelines for individual differences researchers. Personality and Individual Differences, 102, 74-78. https://doi.org/10.1016/j.paid.2016.06.069.

Grove, R., Hoekstra, R. A., Wierda, M., \& Begeer, S. (2018). Special interests and subjective wellbeing in autistic adults. Autism Research, 11(5), 766-775.

Hadad, B.-S., Schwartz, S., \& Binur, N. (2019). Reduced perceptual specialization in autism: Evidence from the other-race face effect. Journal of Experimental Psychology: General, 148(3), 588-594. https://doi. org/10.1037/xge0000550.

Happé, F., Ronald, A., \& Plomin, R. (2006). Time to give up on a single explanation for autism. Nature Neuroscience, 9(10), 1218-1220.

Hayes, A. F. (2013). Introduction to mediation, moderation, and conditional process analysis: A regressionbased approach. New York: Guilford Press.

Hayes, N., \& Joseph, S. (2003). Big 5 correlates of three measures of subjective well-being. Personality and Individual Differences, 34(4), 723-727. https://doi.org/10.1016/S0191-8869(02)00057-0.

Heller, A. S., van Reekum, C. M., Schaefer, S. M., Lapate, R. C., Radler, B. T., Ryff, C. D., et al. (2013). Sustained striatal activity predicts eudaimonic well-being and cortisol output. Psychological Science, 24(11), 2191-2200. https://doi.org/10.1177/0956797613490744.

Hoekstra, R. A., Bartels, M., Verweij, C. J. H., \& Boomsma, D. I. (2007). Heritability of autistic traits in the general population. Archives of Pediatrics and Adolescent Medicine, 161(4), 372-377. https://doi. org/10.1001/archpedi.161.4.372.

Hurley, R. S. E., Losh, M., Parlier, M., Reznick, J. S., \& Piven, J. (2007). The broad autism phenotype questionnaire. Journal of Autism and Developmental Disorders, 37(9), 1679-1690. https://doi.org/10.1007/ s10803-006-0299-3.

Jamil, R., Gragg, M. N., \& DePape, A. M. (2017). The broad autism phenotype: Implications for empathy and friendships in emerging adults. Personality and Individual Differences, 111, 199-204. https://doi. org/10.1016/j.paid.2017.02.020.

Jobe, L. E., \& White, S. W. (2007). Loneliness, social relationships, and a broader autism phenotype in college students. Personality and Individual Differences, 42(8), 1479-1489. https://doi.org/10.1016/j. paid.2006.10.021.

John, O. P., Donahue, E. M., \& Kentle, R. L. (1991). The big five inventory-Versions 4a and 54. Berkeley, CA: University of California, Berkeley, Institute of Personality and Social Research. 
John, O. P., \& Srivastava, S. (1999). The Big Five trait taxonomy: History, measurement, and theoretical perspectives. In L. Pervin \& O. P. John (Eds.), Handbook of personality: Theory and research (2nd ed., Vol. 2, pp. 102-138). New York: Guilford Press.

Kang, E., Gadow, K. D., \& Lerner, M. D. (2019). Atypical communication characteristics, differential diagnosis, and the autism spectrum disorder phenotype in youth. Journal of Clinical Child \& Adolescent Psychology. https://doi.org/10.1080/15374416.2018.1539912.

Keyes, C. L. M. (2005). Chronic physical conditions and aging: Is mental health a potential protective factor? Ageing International, 30(1), 88-104. https://doi.org/10.1007/BF02681008.

Kim, H., Keifer, C., Rodriguez-Seijas, C., Eaton, N., Lerner, M., \& Gadow, K. (2018). Quantifying the optimal structure of the autism phenotype: A comprehensive comparison of dimensional, categorical, and hybrid models. Journal of the American Academy of Child and Adolescent Psychiatry. https://doi. org/10.1016/J.JAAC.2018.09.431.

Kim, E. S., Sun, J. K., Park, N., Kubzansky, L. D., \& Peterson, C. (2013). Purpose in life and reduced risk of myocardial infarction among older U.S. adults with coronary heart disease: A two-year follow-up. Journal of Behavioral Medicine, 36(2), 124-133. https://doi.org/10.1007/s1086 5-012-9406-4.

Kokko, K., Tolvanen, A., \& Pulkkinen, L. (2013). Associations between personality traits and psychological well-being across time in middle adulthood. Journal of Research in Personality, 47(6), 748-756.

Kroenke, K., Spitzer, R. L., \& Williams, J. B. W. (2003). The Patient Health Questionnaire-2: Validity of a two-item depression screener. Medical Care, 41(11), 1284-1292. https://doi.org/10.1097/01. MLR.0000093487.78664.3C.

Kroenke, K., Spitzer, R. L., Williams, J. B., \& Löwe, B. (2009). An ultra-brief screening scale for anxiety and depression: The PHQ-4. Psychosomatics, 50(6), 613-621.

Langlois, A., \& Anderson, D. E. (2002). Resolving the quality of life/wellbeing puzzle: Toward a new model. Canadian Journal of Regional Science, 25(3), 501-512.

Lasgaard, M., Nielsen, A., Eriksen, M. E., \& Goossens, L. (2010). Loneliness and social support in adolescent boys with autism spectrum disorders. Journal of Autism and Developmental Disorders, 40(2), 218-226.

Lawson, R. P., Mathys, C., \& Rees, G. (2017). Adults with autism overestimate the volatility of the sensory environment. Nature Neuroscience, 20(9), 1293.

Lindfors, P., \& Lundberg, U. (2002). Is low cortisol release an indicator of positive health? Stress and Health, 18(4), 153-160. https://doi.org/10.1002/smi.942.

Lykken, D., \& Tellegen, A. (1996). Happiness is a stochastic phenomenon. Psychological Science, 7(3), 3-6.

Myers, D. G., \& Diener, E. (1995). Who is happy? Psychological Science, 6(1), 10-19. https://doi. org/10.1111/j.1467-9280.1995.tb00298.x.

O'brien, R. M. (2007). A caution regarding rules of thumb for variance inflation factors. Quality \& Quantity, 41(5), 673-690.

Pavot, W., Diener, E., \& Fujita, F. (1990). Extraversion and happiness. Personality and Individual Differences, 11(12), 1299-1306.

Pisula, E., Danielewicz, D., Kawa, R., \& Pisula, W. (2015). Autism spectrum quotient, coping with stress and quality of life in a non-clinical sample-An exploratory report. Health and Quality of Life Outcomes, 13(1), 173. https://doi.org/10.1186/s12955-015-0370-x.

Piven, J., Palmer, P., Jacobi, D., Childress, D., \& Arndt, S. (1997). Broader autism phenotype: Evidence from a family history study of multiple-incidence autism families. American Journal of Psychiatry, 154(2), 185-190. https://doi.org/10.1176/ajp.154.2.185.

Preacher, K. J., \& Hayes, A. F. (2004). SPSS and SAS procedures for estimating indirect effects in simple mediation models. Behavior Research Methods, Instruments, \& Computers, 36(4), 717-731.

Radtke, M., Wieczoreková, D., Normann, C., Humpolicek, P., Brakemeier, E. L., Bubl, E., et al. (2019). Exploring autistic traits in adults with chronic depression: A clinical study. Research in Autism Spectrum Disorders, 65, 34-45.

Ratner, K., \& Burrow, A. L. (2017). Autistic features in the general population: Implications for sensing purpose in life. The Journal of Positive Psychology, 9760, 1-8. https://doi.org/10.1080/17439 760.2017.1315647.

Robbins, M., Francis, L. J., \& Edwards, B. (2010). Happiness as stable extraversion: Internal consistency reliability and construct validity of the oxford happiness questionnaire among undergraduate students. Current Psychology, 29(2), 89-94. https://doi.org/10.1007/s12144-010-9076-8.

Robinson, E. B., Koenen, K. C., McCormick, M. C., Munir, K., Hallett, V., Happe, F., et al. (2011). Evidence that autistic traits show the same etiology in the general population and at the quantitative 
extremes (5\%, 2.5\%, and 1\%). Archives of General Psychiatry, 68(11), 1113-1121. https://doi. org/10.1001/archgenpsychiatry.2011.119.

Ryff, C. D. (1989). Happiness is everything, or is it? Explorations on the meaning of psychological well-being. Journal of Personality and Social Psychology, 57(6), 1069-1081. https://doi. org/10.1037/034645.

Ryff, C. D. (2014). Psychological well-being revisited: Advances in the science and practice of eudaimonia. Psychotherapy and Psychosomatics, 83(1), 10-28. https://doi.org/10.1159/000353263.

Sarason, I. G., Levine, H. M., Basham, R. B., \& Sarason, B. R. (1983). Assessing social support: The social support questionnaire. Journal of Personality and Social Psychology, 44(1), 127.

Sasson, N. J., Nowlin, R. B., \& Pinkham, A. E. (2012). Social cognition, social skill, and the broad autism phenotype. Autism, 17(6), 655-667. https://doi.org/10.1177/1362361312455704.

Schulz, R., \& Sherwood, P. R. (2008). Physical and mental health effects of family caregiving. Journal of Social Work Education, 44(sup3), 105-113. https://doi.org/10.5175/JSWE.2008.773247702.

Segrin, C., \& Taylor, M. (2007). Positive interpersonal relationships mediate the association between social skills and psychological well-being. Personality and Individual Differences, 43(4), 637-646.

Spitzer, R. L., Kroenke, K., Williams, J. B. W., \& Löwe, B. (2006). A brief measure for assessing generalized anxiety disorder: The GAD-7. Archives of Internal Medicine, 166(10), 1092-1097. https://doi. org/10.1001/archinte.166.10.1092.

Starr, E., Berument, S. K., Pickles, A., Tomlins, M., Bailey, A., Papanikolaou, K., et al. (2001). A family genetic study of autism associated with profound mental retardation. Journal of Autism and Developmental Disorders, 31(1), 89-96. https://doi.org/10.1023/A:1005669915105.

Sucksmith, E., Roth, I., \& Hoekstra, R. A. (2011). Autistic traits below the clinical threshold: Re-examining the broader autism phenotype in the 21st century. Neuropsychology Review, 21(4), 360-389. https:// doi.org/10.1007/s11065-011-9183-9.

Taggart, F., Stewart-Brown, S., \& Parkinson, J. (2015). Warwick-Edinburgh mental well-being scale (WEMWBS) user guide-Version 2. Edinburgh, UK: NHS Health Scotland.

Vickerstaff, S., Heriot, S., Wong, M., Lopes, A., \& Dossetor, D. (2007). Intellectual ability, self-perceived social competence, and depressive symptomatology in children with high-functioning autistic spectrum disorders. Journal of Autism and Developmental Disorders, 37(9), 1647-1664.

Wainer, A. L., Ingersoll, B. R., \& Hopwood, C. J. (2011). The structure and nature of the broader autism phenotype in a non-clinical sample. Journal of Psychopathology and Behavioral Assessment, 33(4), 459-469. https://doi.org/10.1007/s10862-011-9259-0.

Wakabayashi, A., Baron-Cohen, S., \& Wheelwright, S. (2006). Are autistic traits an independent personality dimension? A study of the Autism-Spectrum Quotient (AQ) and the NEO-PI-R. Personality and Individual Differences, 41(5), 873-883.

Yates, M. E., Tennstedt, S., \& Chang, B.-H. (1999). Contributors to and mediators of psychological wellbeing for informal caregivers. The Journals of Gerontology Series B: Psychological Sciences and Social Sciences, 54(1), 12-22. https://doi.org/10.1093/geronb/54B.1.P12.

Publisher's Note Springer Nature remains neutral with regard to jurisdictional claims in published maps and institutional affiliations. 